\title{
Outcomes and National Trends for the Surgical Treatment of Lumbar Spine Trauma
}

\author{
Doniel Drazin, ${ }^{1}$ Miriam Nuno, ${ }^{1}$ Faris Shweikeh, ${ }^{1,2}$ Alexander R. Vaccaro, ${ }^{3}$ Eli Baron, \\ Terrence T. Kim, ${ }^{4}$ and J. Patrick Johnson ${ }^{1,5}$ \\ ${ }^{1}$ Department of Neurosurgery, Cedars-Sinai Medical Center, Los Angeles, CA 90048, USA \\ ${ }^{2}$ Department of Surgery, University of Arizona College of Medicine, Tucson, AZ 85724, USA \\ ${ }^{3}$ Department of Orthopedic Surgery, Thomas Jefferson University, Philadelphia, PA 19107, USA \\ ${ }^{4}$ Department of Orthopedics, Cedars-Sinai Medical Center, Los Angeles, CA 90048, USA \\ ${ }^{5}$ Department of Neurosurgery, University of California Davis Medical Center, Sacramento, CA 95820, USA
}

Correspondence should be addressed to Doniel Drazin; ddrazin@gmail.com

Received 13 February 2016; Revised 21 May 2016; Accepted 22 May 2016

Academic Editor: Panagiotis Korovessis

Copyright (C) 2016 Doniel Drazin et al. This is an open access article distributed under the Creative Commons Attribution License, which permits unrestricted use, distribution, and reproduction in any medium, provided the original work is properly cited.

Introduction. Operative treatment of lumbar spine compression fractures includes fusion and/or cement augmentation. Our aim was to evaluate postoperative differences in patients treated surgically with fusion, vertebroplasty, or kyphoplasty. Methods. The Nationwide Inpatient Sample Database search for adult vertebral compression fracture patients treated 2004-2011 identified 102,316 surgical patients: $30.6 \%$ underwent spinal fusion, $17.1 \%$ underwent kyphoplasty, and $49.9 \%$ underwent vertebroplasty. Univariate analysis of patient and hospital characteristics, by treatment, was performed. Multivariable analysis was used to determine factors associated with mortality, nonroutine discharge, complications, and patient safety. Results. Average patient age: fusion (46.2), kyphoplasty (78.5), vertebroplasty (76.7) $(p<.0001)$. Gender, race, household income, hospital-specific characteristics, and insurance differences were found $(p \leq .001)$. Leading comorbidities were hypertension, osteoporosis, and diabetes. Risks for higher mortality (OR 2.0: CI: 1.6-2.5), nonroutine discharge (OR 1.6, CI: 1.6-1.7), complications (OR 1.1, CI: 1.0-1.1), and safety related events (OR 1.1, CI: 1.0-1.1) rose consistently with increasing age, particularly among fusion patients. Preexisting comorbidities and longer in-hospital length of stay were associated with increased odds of nonroutine discharge, complications, and patient safety. Conclusions. Fusion patients had higher rates of poorer outcomes compared to vertebroplasty and kyphoplasty cohorts. Mortality, nonroutine discharge, complications, and adverse events increased consistently with older age.

\section{Introduction}

Lumbar compression fractures are among the most common medical and surgical conditions encountered by spinal surgeons [1]. Approximately 1.4 million patients sustain vertebral compression fractures every year [2], with an annual inpatient cost just under $\$ 5$ billion [3]. Compression fractures disproportionately affect the elderly (65+ years) secondary to osteoporosis, which is responsible for $>700,000$ spinal fracture cases in the United States annually [4]. Although traumatic lumbar fractures represent a small portion in all trauma patients, their physical and financial burden on patients are more significant than other injuries [5].

Standard treatment of vertebral compression fractures consists of conservative management, including bed rest, bracing, and analgesics [6]. Studies, however, have noted that these practices are often insufficient in improving pain and mobility of these patients [7-9]. Operative interventions, namely, surgical fusion with instrumentation and cement augmentation procedures, have been gaining popularity [10, 11] as studies have shown both short-term physical improvements [12-14] and long-term survival benefits $[15,16]$ in select patients undergoing surgical intervention for compression fractures.

Numerous studies have looked at national trends and outcomes of cement augmentation procedures (vertebroplasty and kyphoplasty) for vertebral compression fractures [13, 15-18]. These studies, however, do not evaluate differences in demographics and outcomes among surgical fusion, 
kyphoplasty, and vertebroplasty procedures performed for vertebral compression fractures. This study evaluates patient demographics and hospital characteristics associated with each type of treatment as well as assessing potential outcome differences between patients undergoing fusion, vertebroplasty, and kyphoplasty for vertebral compression fracture.

\section{Methods}

2.1. Data Source and Cohort Selection. We utilized the Nationwide Inpatient Sample (NIS) database to capture vertebral fracture patients that underwent vertebral cement augmentation procedures in US hospitals between 2004 and 2011. Using International Classification of DiseasesNinth Revision-Clinical Modification (ICD-9-CM) codes, we identified adult patients 18 years of age or older with primary diagnosis of lumbar fracture (ICD-9-CM: 805.4, 806.4); only patients that underwent a fusion (ICD-9-CM: 81.081.08 ), kyphoplasty (ICD-9-CM: 81.65), or vertebroplasty (ICD-9-CM: 81.66) according to the five leading procedures documented were included. Patients who underwent spine augmentation for a vertebral fracture secondary to malignancy according to the leading five diagnoses of cancer (ICD9, 1400-1991, 2000-2089) were excluded from this analysis.

2.2. Patient Population and Hospital Characteristics. Demographics considered included patients' age, gender, race, medical insurance, median income, and preexisting comorbidities. Hospital characteristics such as number of beds, teaching status, region, and location were documented. Age was analyzed as a continuous variable using the following categories: $18-44,45-64,65-84$, and $85+$. In terms of percentages, data was missing for gender $(0.07 \%)$, race $(21.9 \%)$, insurance $(0.02 \%)$, median income $(2.1 \%)$, hospital bed size (2.7\%), teaching status (2.7\%), and hospital location (2.7\%).

2.3. Outcomes of Interest. In-hospital mortality, nonroutine discharge, complications, patient safety indicators, inhospital length of stay (LOS), and total charges were considered in this study. A discharge other than discharge to home (e.g., transfer, mortality) was considered nonroutine. The following adverse events were considered in the overall complication rate: neurological, pulmonary, thromboembolic, cardiac, procedure related, medical, peripheral vascular, infection, fluid, and electrolyte abnormalities, cerebrospinal fluid rhinorrhea, stroke, and bleeding.

2.4. Statistical Analysis. Descriptive statistics were used to summarize patient and hospital characteristics. Bivariate analysis was used to determine differences in patient/hospital characteristics and outcomes according to the type of intervention experienced (e.g., cement augmentation and fusion). Odds ratio (OR), 95\% confidence intervals (CI), interquartile range (IQR), standard deviation (SD), and corresponding $p$ values were reported. US nationwide estimates were performed using SAS PROC SURVEY methodology. All analyses used SAS version 9.1 for Windows (SAS Institute Inc., Cary, $\mathrm{NC})$. A $p$ value $\leq .05$ was considered statistically significant.

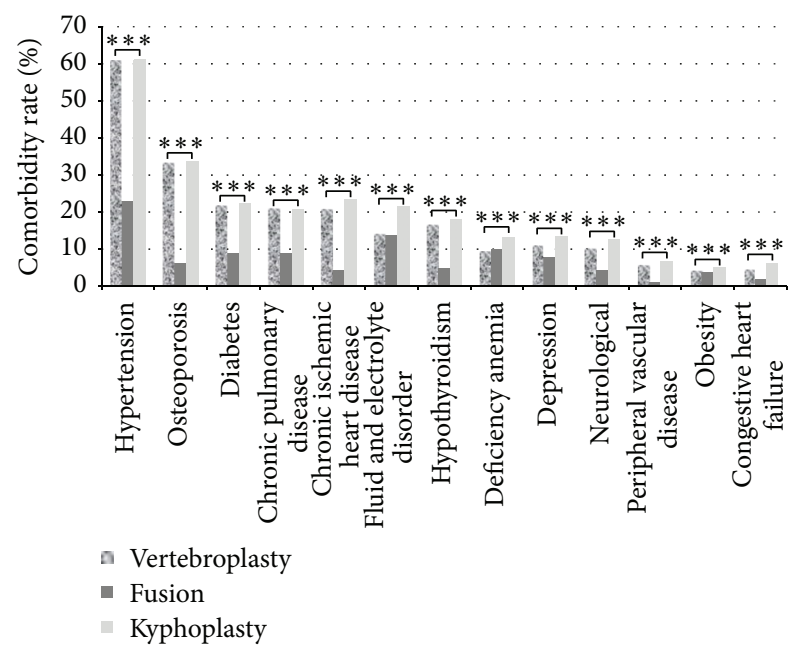

FIGURE 1: Distribution of comorbidities for vertebral compression fracture patients that underwent a fusion, kyphoplasty, or vertebroplasty between 2000 and $2011(N=102,316) .{ }^{* * *} p<.0001$.

\section{Results}

3.1. Demographics. A total of 102,316 vertebral fracture patients underwent a cement augmentation or spinal fusion procedure between 2004 and 2011. A subset of 31,332 (30.6\%) were treated with fusion, 17,456 (17.1\%) underwent a kyphoplasty, 51,021 (49.9\%) underwent a vertebroplasty, and the remaining 2,507 (2.5\%) had multiple procedures (Table 1$)$. Patients that underwent a fusion were significantly younger than the kyphoplasty and vertebroplasty cohorts, 46.2 versus 78.5 and 76.7 , respectively $(p<.0001)$. Only $1.6 \%$ of fusion patients were of age 85+ compared to significant rates found in kyphoplasty (33.1\%) and vertebroplasty cohorts (27.6\%). There were significantly fewer white patients in the fusion (79.5\%) cohort compared to kyphoplasty $(87.5 \%)$ and vertebroplasty cohorts $(88.1 \%)(p<.0001)$. Significantly more fusion patients had private insurance $(46.8 \%)$ compared to kyphoplasty (11.4\%) and vertebroplasty cohorts $(12.9 \%)(p<$ .0001). Differences according to median household income were also documented according to augmentation procedure type $(p=.0002)$.

Hospital characteristics according to the type of augmentation procedure were also consistently significant (Table 2). More fusion patients were treated in large hospitals, teaching hospitals, and urban hospitals compared to the kyphoplasty, vertebroplasty, and multiple surgery cohorts (Table 2). A detailed description of preexisting comorbidities according to surgical procedure type is illustrated in Figure 1. Overall, hypertension followed by osteoporosis and diabetes seemed to be the most common conditions. Fusion patients had consistently and significantly $(p<.0001)$ fewer comorbidities compared to kyphoplasty and vertebroplasty cohorts, independently of the type of comorbidity.

3.2. Univariate Analysis Outcomes. The overall mortality rate was $0.5 \%$, with a leading rate of $0.8 \%$ among patients that underwent a fusion, $0.7 \%$ for kyphoplasty, $0.3 \%$ for 
TABLE 1: Characteristics of 102,316 vertebral compression fracture patients that underwent vertebral augmentation procedures between 2004 and 2011 .

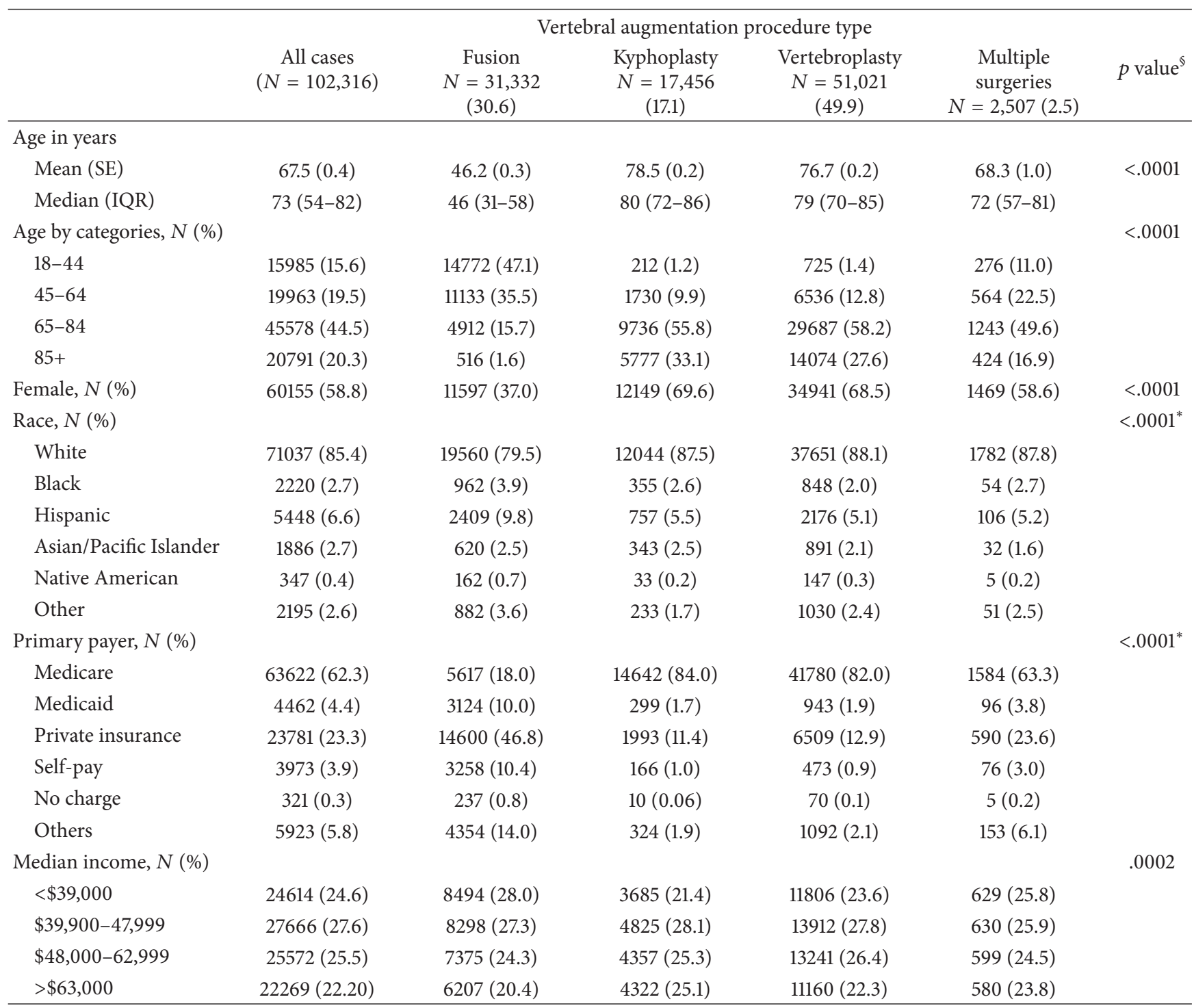

Rounded percent (\%); missing data rates: female (.06), race (18.7), primary payer (.23), and median income (2.1).

${ }^{\S}$ Comparisons between fusion, kyphoplasty, and vertebroplasty cohorts; ${ }^{*}$ comparisons: white versus others and private versus nonprivate.

vertebroplasty, and $1.4 \%$ for multiple procedures cohort $(p<$ .0001 , Table 3). Approximately half of all patients (55.4\%) were discharged nonroutinely. Kyphoplasty patients were more likely to be discharged nonroutinely compared to fusion $(51.7 \%)$ and vertebroplasty patients $(52.7 \%)$ and patients that underwent multiple surgeries (64.3\%). The highest rates of complications were documented among patients that underwent multiple surgeries (25.4\%), followed by fusion patients (24.0\%), kyphoplasty patients (21.4\%), and vertebroplasty patients (16.0\%). Similarly, fusion patients experienced significantly more adverse safety events (13.5\%) when compared to kyphoplasty $(8.8 \%)$, vertebroplasty $(6.5 \%)$, and multiple procedures patients $(12.0 \%)(p<.0001)$.

The average overall in-hospital length of stay was 6.5 days (Table 3). Patients that underwent a fusion spent a significantly $(p<.0001)$ longer hospitalization period (9.8 days) compared to the multiple surgeries cohort (7.5 days), kyphoplasty cohort (5.8 days), and vertebroplasty cohort (4.6 days). Fusion patients spent an average of $\$ 113,067$, while patients that underwent multiple procedures spent an average of $\$ 74,047(p<.0001)$. Kyphoplasty $(\$ 34,363)$ and vertebroplasty $(\$ 42,459)$ patients had significantly lower total charges.

3.3. Multivariable Analysis of Patient Outcomes. After adjusting for patient's age, race, gender, type of insurance, preexisting comorbidities, and length of in-hospital stay, we found that older age was significantly associated with an increased risk of mortality (OR 2.0, CI: 1.6-2.5), nonroutine discharge (OR 1.6, CI: 1.6-1.7), complication (OR 1.1, CI: 1.0-1.1), and safety adverse events (OR 1.1, CI: 1.0-1.1) (Table 4). Increasing preexisting conditions and longer in-hospital length of 
TABLE 2: Hospital characteristics of 102,316 vertebral compression fracture patients that underwent vertebral augmentation procedures between 2004 and 2011.

\begin{tabular}{|c|c|c|c|c|c|c|}
\hline & & & al augmentatio & cedure type & & \\
\hline & $\begin{array}{c}\text { All cases } \\
(N=102,316)\end{array}$ & $\begin{array}{c}\text { Fusion } \\
N=31,332 \\
(30.6)\end{array}$ & $\begin{array}{c}\text { Kyphoplasty } \\
N=17,456 \\
(17.1)\end{array}$ & $\begin{array}{c}\text { Vertebroplasty } \\
\qquad \begin{array}{c}N=51,021 \\
(49.9)\end{array}\end{array}$ & $\begin{array}{c}\text { Multiple } \\
\text { surgeries } \\
N=2,507(2.5)\end{array}$ & $p$ value ${ }^{\S}$ \\
\hline Hospital bed size, $N(\%)$ & & & & & & .001 \\
\hline Small & $7442(7.4)$ & $1341(4.3)$ & $1539(8.9)$ & $4410(8.7)$ & $152(6.2)$ & \\
\hline Medium & $24182(23.9)$ & $6928(22.4)$ & $4011(23.1)$ & $12580(24.9)$ & $664(27.1)$ & \\
\hline Large & $69525(68.7)$ & $22617(73.2)$ & $11792(68.0)$ & $33482(66.3)$ & $1635(66.7)$ & \\
\hline Teaching hospital, $N$ (\%) & & & & & & $<.0001$ \\
\hline Yes & $49599(49.0)$ & $21819(70.6)$ & $7944(45.8)$ & $18595(36.8)$ & $1241(50.6)$ & \\
\hline No & $51550(51.0)$ & $9066(29.4)$ & $9397(54.2)$ & $31877(63.2)$ & $1210(49.4)$ & \\
\hline Hospital region, $N(\%)$ & & & & & & $<.0001$ \\
\hline Northeast & $12556(12.3)$ & $4401(14.0)$ & $1666(9.5)$ & $6113(12.0)$ & $376(15.0)$ & \\
\hline Midwest & $22374(21.9)$ & $6942(22.2)$ & $5025(28.8)$ & 9905 (19.4) & $501(20.0)$ & \\
\hline South & $49935(48.8)$ & $13428(42.9)$ & $7296(41.8)$ & $27996(54.9)$ & $1216(48.5)$ & \\
\hline West & $17451(17.1)$ & $6561(20.9)$ & $3469(19.9)$ & 7007 (13.7) & $414(16.5)$ & \\
\hline Hospital location, $N(\%)$ & & & & & & .0003 \\
\hline Rural & $6042(6.0)$ & $953(3.1)$ & $1182(6.8)$ & $3776(7.5)$ & $130(5.3)$ & \\
\hline Urban & $95108(94.0)$ & $29932(96.9)$ & $16159(93.2)$ & $46696(92.5)$ & $2321(94.7)$ & \\
\hline
\end{tabular}

Rounded percent (\%); missing data rates: female (.06), race (18.7), primary payer (.23), median income (2.1), and hospital data (1.1).

${ }^{\S}$ Comparisons between fusion, kyphoplasty, and vertebroplasty cohorts.
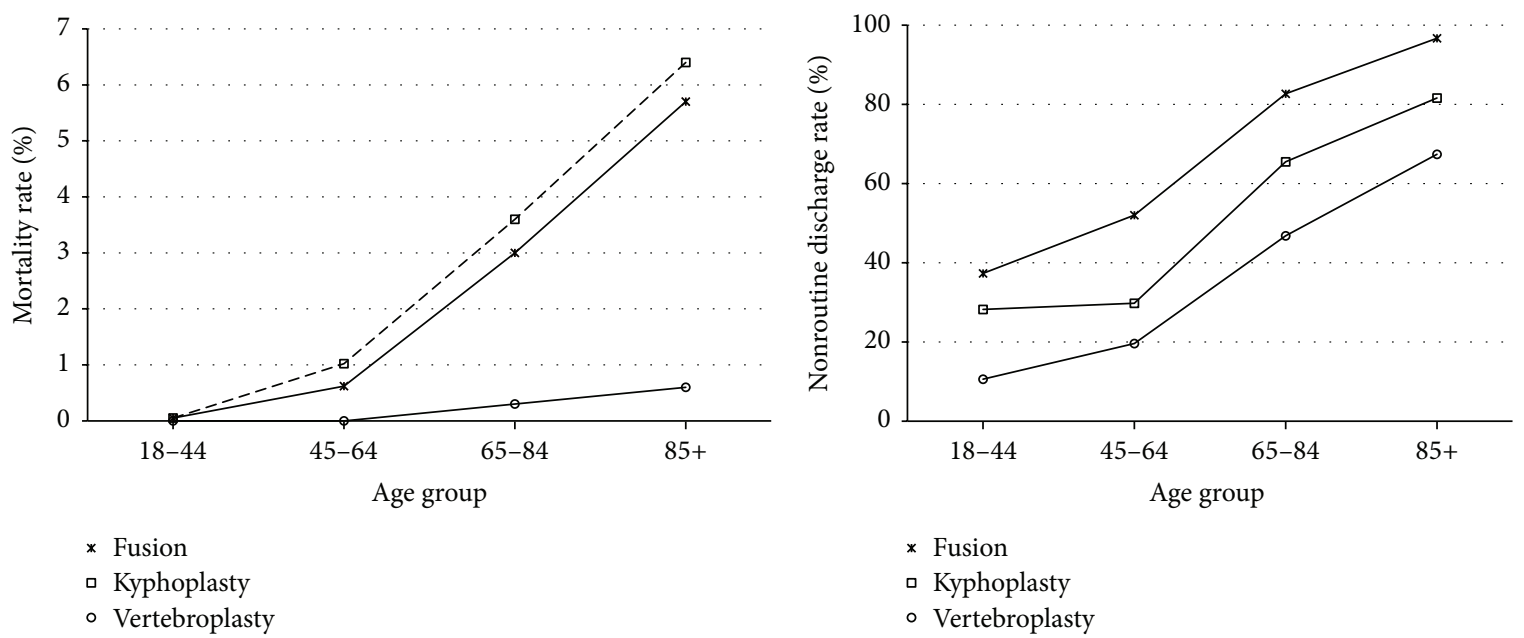

Figure 2: Mortality and nonroutine discharge rates by surgical procedure type and age $(N=102,316)$.

stays were also significantly associated with higher odds of mortality, nonroutine discharge, complications, and safety related events $(p<.0001)$. Patients that underwent a fusion procedure had significantly higher odds of mortality (OR 6.2, CI: 3.4-11.3), nonroutine discharge (OR 2.9, CI: 2.5-3.4), complication (OR 2.2, CI: 1.9-2.6), and safety related event (OR 1.8, CI: 1.5-2.2) compared to the vertebroplasty cohort. White patients seemed to have a significant increased risk of a complication (OR 1.2, CI; 1.0-1.4) and safety related event (OR 1.2: 1.0-1.5) compared to nonwhite patients.
3.4. Outcome Trends by Age and Surgical Procedure. A consistently increasing trend in mortality as well as nonroutine discharge was observed among fusion, kyphoplasty, and vertebroplasty patients with older age (Figure 2). Patients that underwent a vertebroplasty had consistently higher mortality independently of age. Similarly, fusion patients had consistently higher rates of mortality independently of age. Fusion patients had higher nonroutine discharge rates compared to all cohorts independently of age. Fusion patients had significantly higher rates of safety indicators and 
TABLE 3: Outcomes of 102,316 vertebral compression fracture patients that underwent vertebral augmentation procedures between 2004 and 2011.

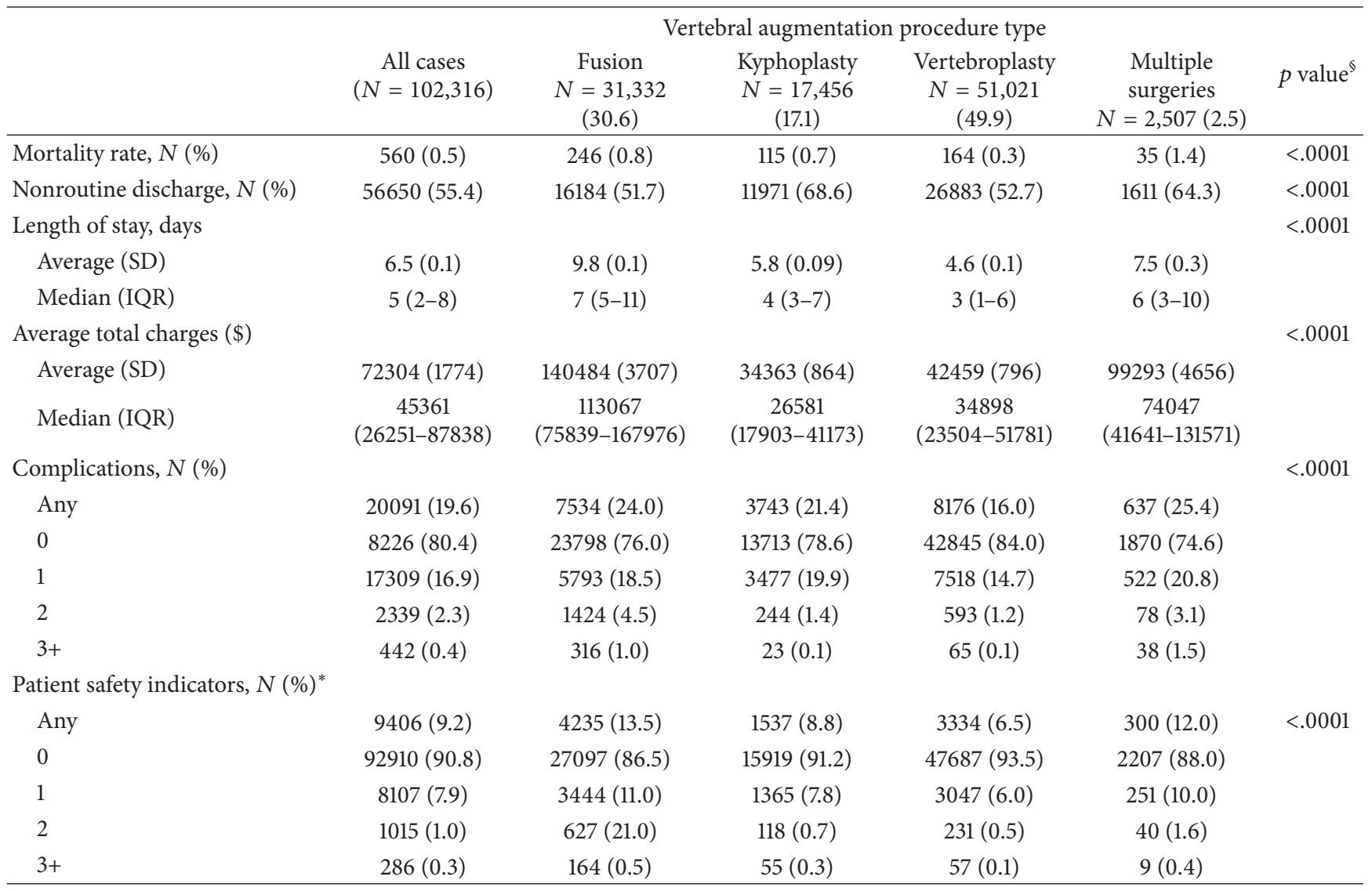

Rounded percent (\%).

${ }^{\S}$ Comparisons between fusion, kyphoplasty, and vertebroplasty cohorts.
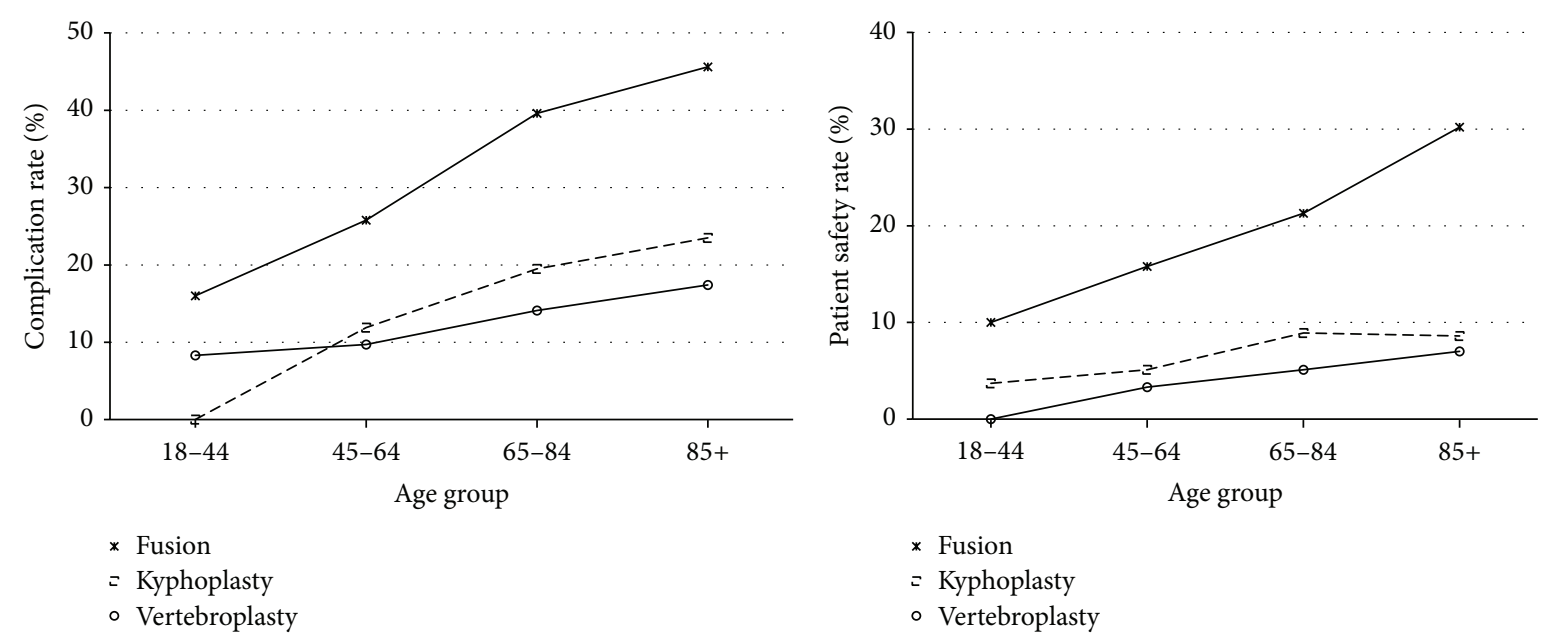

Figure 3: Complication and patient safety rates by surgical procedure type and age $(N=102,316)$.

complications compared to all other cohorts, independently of age (Figure 3).

\section{Discussion}

Lumbar compression fractures represent a leading cause of morbidity and mortality in the United States. Understanding the role of different surgical treatments in survival, complications, and other outcomes of interest is imperative in order to determine optimum treatment modalities. With increasing evidence supporting surgical intervention for these patients $[12,15,16,19-23]$, numerous studies have sought to compare outcomes among different treatment paradigms $[6,12,15$, $17,24,25]$. Surgical fusion with instrumentation and cement 


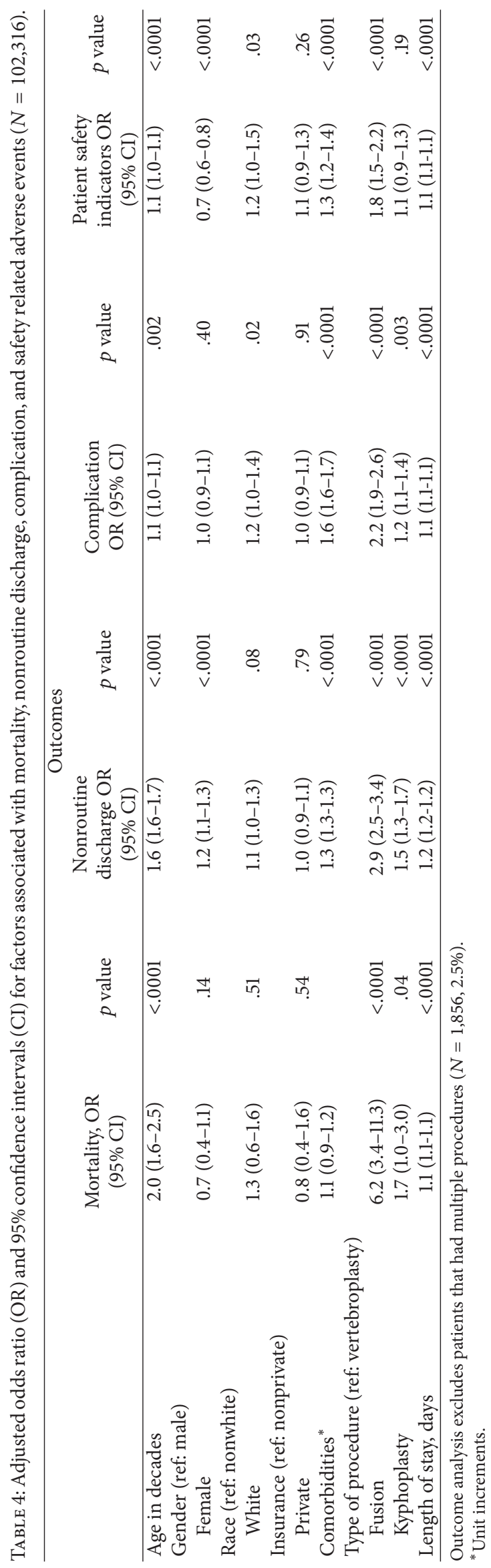


augmentation have been of primary interest, as both procedures have seen increased utilization from the early $1990 \mathrm{~s}$ to 2000 s (12.9\% for cement augmentation patients and $39 \%$ for surgical fusion) [26, 27]. Although numerous studies have compared outcomes between nonsurgical intervention, vertebroplasty, and kyphoplasty [12, 13, 15, 17, 18, 27], there have been no published studies comparing outcomes between vertebroplasty, kyphoplasty, and surgical fusion. The goal of our study was to evaluate differences in demographics and hospital characteristics as well as compare postsurgical outcomes between vertebroplasty, kyphoplasty, and fusion patients with the primary diagnosis of vertebral compression fractures.

Our findings suggest a slight female preponderance $(58.8 \%)$ of patients undergoing surgery for lumbar spine trauma, with significantly more females receiving kyphoplasty $(69.6 \%)$ and vertebroplasty $(68.5 \%)$ compared to spinal fusion $(37.0 \%)$. In the United States, the risk of developing a fragility fracture is up to $40 \%$ for women and $13 \%$ for men over the age of 50 [28]. More specifically, vertebral compression fractures occur in approximately $16 \%$ of all postmenopausal women [29]. In our cohort, $64.8 \%$ of lumbar trauma patients undergoing surgical intervention were over the age of 65 . Significantly younger patients underwent surgical fusion (46.2 years) versus kyphoplasty (78.5 years) and vertebroplasty (76.7 years) procedures. This is consistent with an institutional study by Hsieh et al., which reported significantly older patients in their kyphoplasty versus shortsegment fixation with I-VEP cohort [30]. Lad et al. reported that, within their cohort of vertebral spinal fracture patients, a majority were women and over the age of 65 [27]. As age and gender may be connected in this population, the explanation of higher percentages of elderly patients and women undergoing augmentation procedures may be related.

The most common mechanisms for the occurrence of lumbar spine trauma include falls, sport accidents, and motor vehicle crashes [31]. However, in elderly patients, osteoporosis is responsible for $>700,000$ vertebral compression fractures in the United States annually [4]. We found that osteoporosis was the second leading comorbidity for all lumbar spine trauma patients, with significantly higher percentages in cement augmentation versus surgical fusion cohorts. The leading comorbidity was hypertension, which is known to have high prevalence in elderly populations [32]. In 1990, the United States Census Bureau estimated that over 16 million Americans will be 85 years or older by the year 2050 [33]. Thus, the effect of age on outcomes and treatment for vertebral compression fracture patients is an important health-care problem of increasing impact. We found that, regardless of procedure, an increase in age is associated with higher nonroutine discharge rates, complication rates, and patient safety rates. Mortality rates for cement augmentation procedures remained relatively stable with increased age, while rates for fusion patients increased dramatically, especially in patients $>65$ years old.

Fusion patients as a whole had consistently higher mortality, complication, nonroutine discharge, and patient safety rates compared to their augmentation counterparts. There were also significantly more fusion procedures performed at large, urban teaching hospitals. Daniels et al. reported similar findings while evaluating hospital-based rates of thoracolumbar spine arthrodesis for patients with spinal fractures. They reported that hospitals with higher volumes of spinal fracture patients had higher fusion rates compared to hospitals treating fewer fracture patients [31]. This may indicate that fusion procedures are more complex in nature, which would explain the younger patients, lower comorbidities of patients, and increased adverse outcomes. Patients who underwent fusion were 6.2 times more likely to experience morality, 2.9 times more likely to have a nonroutine discharge, 2.2 times more likely to have a complication, and 1.8 times more likely to have PSI as compared to vertebroplasty patients. Similarly, kyphoplasty patients had higher percentages of adverse outcomes, such as a $70 \%$ increase in mortality, when compared to vertebroplasty patients. Chen et al. had contrary findings, which suggested that an adjusted risk of death was 20\% lower for kyphoplasty patients versus vertebroplasty patients [15].

In a meta-analysis of literature, Eck et al. evaluated pain relief and risk of complications associated with kyphoplasty and vertebroplasty [25]. Their findings suggest that although both methods of augmentation are effective in relieving pain, there is a significant increase in pain relief for vertebroplasty patients versus kyphoplasty patients [12]. However, it was also reported that vertebroplasty patients had higher rates of complications compared to their kyphoplasty counterparts, including increased cement leakage and higher occurrence of sustaining subsequent vertebral fractures [34, 35]. These inconsistencies in results comparing vertebroplasty and kyphoplasty procedures and lack of studies comparing augmentation procedures to spinal fusion procedures call for further research. Prospective studies with appropriate matching of individuals undergoing each treatment type would address limitations of current studies and lead to more concrete results regarding the clinical outcomes of patients undergoing surgical intervention for lumbar spine trauma [15].

4.1. Limitations. Although utilization of national databases may be advantageous, namely, due to high volume of patients and avoidance of selection bias, there remain considerable limitations. Such limitations include potential coding errors, lack of data specifying type of injury and severity, and absence of long-term outcomes or disability scores [1, 26, 27]. Additionally, the codes and the coding used by physician may not be specific for compression fractures. Populations with operative fractures versus those with fractures treated with kyphoplasty/vertebroplasty are likely completely different with regard to injury severity, neurologic status, and so forth. Our goal in this study was to present the general trend in compression fractures in the elderly population over the years studied. Therefore, our findings should be considered with these points in mind.

\section{Conclusions}

Treatment patterns of patients with vertebral compression fractures differ significantly when comparing patient demographics and hospital type and location. Age and medical 
comorbidities are significant risk factors for mortality and adverse outcomes regardless of procedures. Spinal fusion was associated with higher risk of adverse outcomes compared to cement augmentation. Kyphoplasty was associated with higher risk of adverse outcome compared to vertebroplasty. Elderly patients and those with medical comorbidities appear to strongly have the potential for poorer outcomes regardless of what type of procedure is performed.

\section{Competing Interests}

The authors declare that they have no competing interests.

\section{References}

[1] A. A. Baaj, K. Downes, A. R. Vaccaro, J. S. Uribe, and F. L. Vale, "Trends in the treatment of lumbar spine fractures in the United States: a socioeconomics perspective-clinical article," Journal of Neurosurgery: Spine, vol. 15, no. 4, pp. 367-370, 2011.

[2] O. Johnell and J. A. Kanis, "An estimate of the worldwide prevalence and disability associated with osteoporotic fractures," Osteoporosis International, vol. 17, no. 12, pp. 1726-1733, 2006.

[3] Agency for Healthcare Research and Quality, Healthcare Cost and Utlization Project, Nationwide Inpatient Sample, 2007.

[4] C. Cooper, E. J. Atkinson, W. M. O’Fallon, and L. J. Melton III, "Incidence of clinically diagnosed vertebral fractures: a population-based study in Rochester, Minnesota, 1985-1989," Journal of Bone and Mineral Research, vol. 7, no. 2, pp. 221-227, 1992.

[5] A. R. Vaccaro, H. S. An, S. Lin, S. Sun, R. A. Balderston, and J. M. Cotier, "Noncontiguous injuries of the spine," Journal of Spinal Disorders, vol. 5, no. 3, pp. 320-329, 1992.

[6] S. Boonen, D. A. Wahl, L. Nauroy et al., "Balloon kyphoplasty and vertebroplasty in the management of vertebral compression fractures," Osteoporosis International, vol. 22, no. 12, pp. 29152934, 2011.

[7] I. Hallberg, A. M. Rosenqvist, L. Kartous, O. Löfman, O. Wahlström, and G. Toss, "Health-related quality of life after osteoporotic fractures," Osteoporosis International, vol. 15, no. 10, pp. 834-841, 2004.

[8] S. E. Hall, R. A. Criddle, T. L. Comito, and R. L. Prince, "A case-control study of quality of life and functional impairment in women with long-standing vertebral osteoporotic fracture," Osteoporosis International, vol. 9, no. 6, pp. 508-515, 1999.

[9] G. P. Lyritis, B. Mayasis, N. Tsakalakos et al., "The natural history of the osteoporotic vertebral fracture," Clinical Rheumatology, vol. 8, no. 2, pp. 66-69, 1989.

[10] R. A. Deyo, S. K. Mirza, B. I. Martin, W. Kreuter, D. C. Goodman, and J. G. Jarvik, "Trends, major Medical complications, and charges associated with surgery for lumbar spinal stenosis in older adults," Journal of the American Medical Association, vol. 303, no. 13, pp. 1259-1265, 2010.

[11] S. P. Lad, C. G. Patil, E. M. Lad, M. G. Hayden, and M. Boakye, "National trends in vertebral augmentation procedures for the treatment of vertebral compression fractures," Surgical Neurology, vol. 71, no. 5, pp. 580-585, 2009.

[12] M. J. McGirt, S. L. Parker, J.-P. Wolinsky, T. F. Witham, A. Bydon, and Z. L. Gokaslan, "Vertebroplasty and kyphoplasty for the treatment of vertebral compression fractures: an evidencedbased review of the literature," Spine Journal, vol. 9, no. 6, pp. 501-508, 2009.
[13] R. Buchbinder, R. H. Osborne, P. R. Ebeling et al., "A randomized trial of vertebroplasty for painful osteoporotic vertebral fractures," The New England Journal of Medicine, vol. 361, no. 6, pp. 557-568, 2009.

[14] D. F. Kallmes, B. A. Comstock, P. J. Heagerty et al., "A randomized trial of vertebroplasty for osteoporotic spinal fractures," New England Journal of Medicine, vol. 361, no. 6, pp. 569-579, 2009.

[15] A. T. Chen, D. B. Cohen, and R. L. Skolasky, "Impact of nonoperative treatment, vertebroplasty, and kyphoplasty on survival and morbidity after vertebral compression fracture in the medicare population," Journal of Bone and Joint SurgerySeries A, vol. 95, no. 19, pp. 1729-1736, 2013.

[16] A. A. Edidin, K. L. Ong, E. Lau, and S. M. Kurtz, "Mortality risk for operated and nonoperated vertebral fracture patients in the medicare population," Journal of Bone and Mineral Research, vol. 26, no. 7, pp. 1617-1626, 2011.

[17] V. Goz, T. J. Errico, J. H. Weinreb et al., "Vertebroplasty and kyphoplasty: national outcomes and trends in utilization from 2005 through 2010," Spine Journal, vol. 15, no. 5, pp. 959-965, 2015.

[18] D. F. Kallmes, B. A. Comstock, P. J. Heagerty et al., "A randomized trial of vertebroplasty for osteoporotic spinal fractures," The New England Journal of Medicine, vol. 361, no. 6, pp. 569-579, 2009.

[19] M. H. J. Voormolen, W. P. T. M. Mali, P. N. M. Lohle et al., "Percutaneous vertebroplasty compared with optimal pain medication treatment: short-term clinical outcome of patients with subacute or chronic painful osteoporotic vertebral compression fractures. The VERTOS study," American Journal of Neuroradiology, vol. 28, no. 3, pp. 555-560, 2007.

[20] J. T. Liu, W. J. Liao, W. C. Tan et al., "Balloon kyphoplasty versus vertebroplasty for treatment of osteoporotic vertebral compression fracture: a prospective, comparative, and randomized clinical study," Osteoporosis International, vol. 21, no. 2, pp. 359-364, 2010.

[21] D. Wardlaw, S. R. Cummings, J. Van Meirhaeghe et al., "Efficacy and safety of balloon kyphoplasty compared with non-surgical care for vertebral compression fracture (FREE): a randomised controlled trial," The Lancet, vol. 373, no. 9668, pp. 1016-1024, 2009.

[22] J. Thillainadesan, G. Schlaphoff, K. A. Gibson, G. M. Hassett, and H. P. McNeil, "Long-term outcomes of vertebroplasty for osteoporotic compression fractures," Journal of Medical Imaging and Radiation Oncology, vol. 54, no. 4, pp. 307-314, 2010.

[23] J. J. Verlaan, C. H. Diekerhof, E. Buskens et al., "Surgical treatment of traumatic fractures of the thoracic and lumbar spine: a systematic review of the literature on techniques, complications, and outcome," Spine, vol. 29, no. 7, pp. 803-814, 2004.

[24] Z. N. Irwin, M. Arthur, R. J. Mullins, and R. A. Hart, "Variations in injury patterns, treatment, and outcome for spinal fracture and paralysis in adult versus geriatric patients," Spine, vol. 29, no. 7, pp. 796-802, 2004.

[25] J. C. Eck, D. Nachtigall, S. C. Humphreys, and S. D. Hodges, "Comparison of vertebroplasty and balloon kyphoplasty for treatment of vertebral compression fractures: a meta-analysis of the literature," Spine Journal, vol. 8, no. 3, pp. 488-497, 2008.

[26] J. A. Cowan Jr., J. B. Dimick, R. Wainess, G. R. Upchurch Jr., W. F. Chandler, and F. La Marca, "Changes in the utilization of spinal fusion in the United States," Neurosurgery, vol. 59, no. 1, pp. 15-20, 2006. 
[27] S. P. Lad, C. G. Patil, E. M. Lad, and M. Boakye, "Trends in pathological vertebral fractures in the United States: 1993 to 2004," Journal of Neurosurgery: Spine, vol. 7, no. 3, pp. 305-310, 2007.

[28] N. A. Manson and F. M. Phillips, "Minimally invasive techniques for the treatment of osteoporotic vertebral fractures," The Journal of Bone \& Joint Surgery-American Volume, vol. 88, no. 8, pp. 1862-1872, 2006.

[29] L. D. Cohen, "Fractures of the osteoporotic spine," Orthopedic Clinics of North America, vol. 21, no. 1, pp. 143-150, 1990.

[30] M.-K. Hsieh, L.-H. Chen, and W.-J. Chen, "Current concepts of percutaneous balloon kyphoplasty for the treatment of osteoporotic vertebral compression fractures: evidence-based review," Biomedical Journal, vol. 36, no. 4, pp. 154-161, 2013.

[31] A. H. Daniels, M. Arthur, and R. A. Hart, "Variability in rates of arthrodesis for patients with thoracolumbar spine fractures with and without associated neurologic injury," Spine, vol. 32, no. 21, pp. 2334-2338, 2007.

[32] "National High Blood Pressure Education Program Working Group Report on Hypertension in the Elderly. National High Blood Pressure Education Program Working Group," Hypertension, vol. 23, no. 3, pp. 275-285, 1994.

[33] American Association of Retired Persons, A Profile of Older Americans, American Association of Retired Persons, Washington, DC, USA, 1990.

[34] A.-M. Kelly, "Does the clinically significant difference in visual analog scale pain scores vary with gender, age, or cause of pain?" Academic Emergency Medicine, vol. 5, no. 11, pp. 1086-1090, 1998.

[35] A. Komemushi, N. Tanigawa, S. Kariya et al., "Percutaneous vertebroplasty for osteoporotic compression fracture: multivariate study of predictors of new vertebral body fracture," CardioVascular and Interventional Radiology, vol. 29, no. 4, pp. 580-585, 2006. 


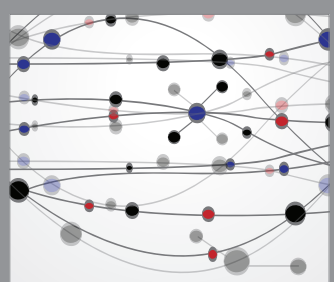

The Scientific World Journal
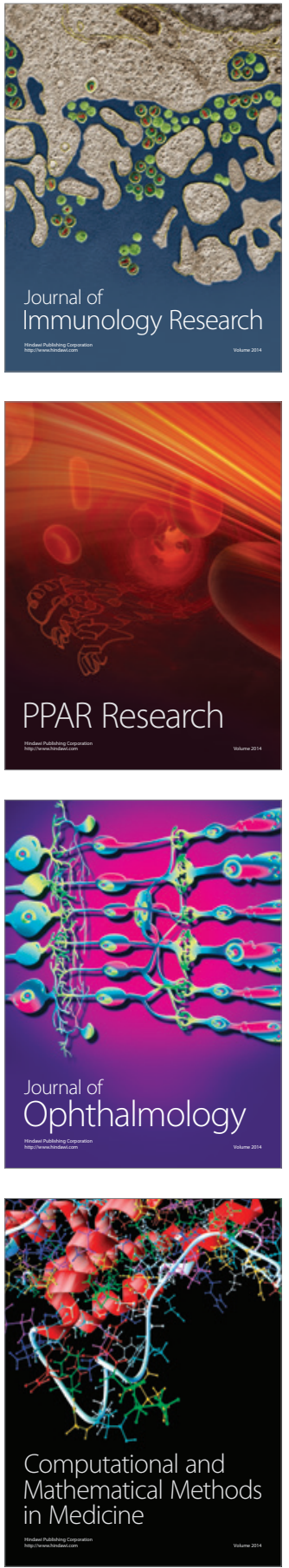

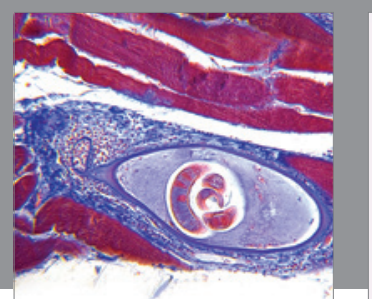

Gastroenterology Research and Practice

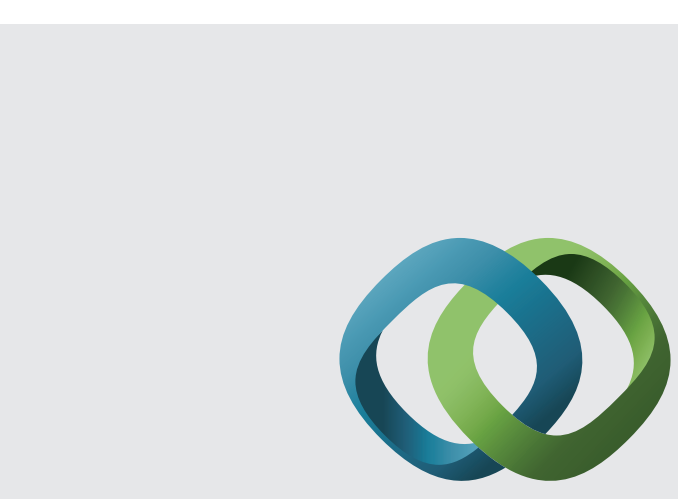

\section{Hindawi}

Submit your manuscripts at

http://www.hindawi.com
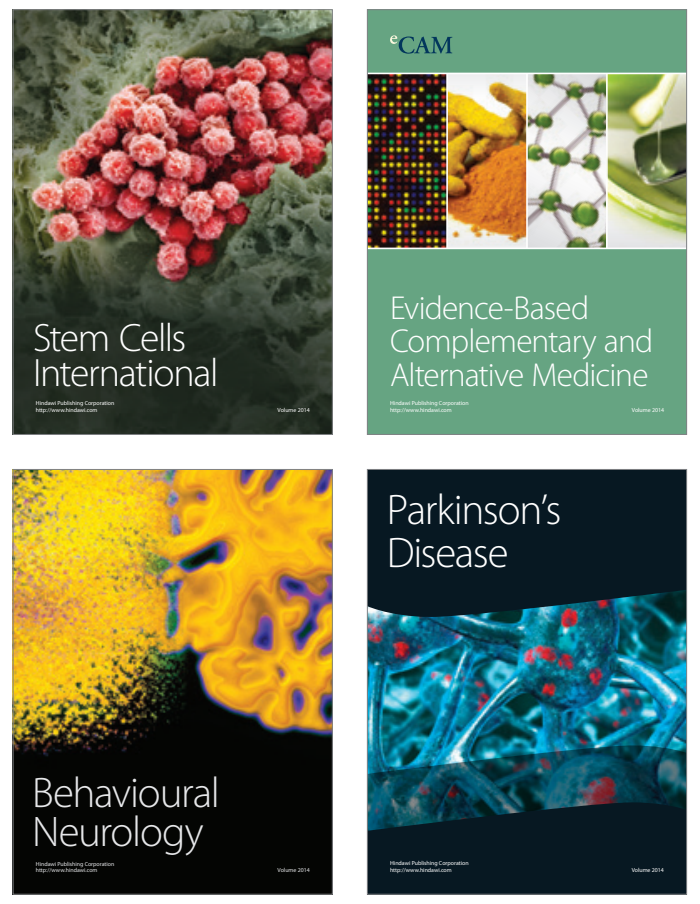
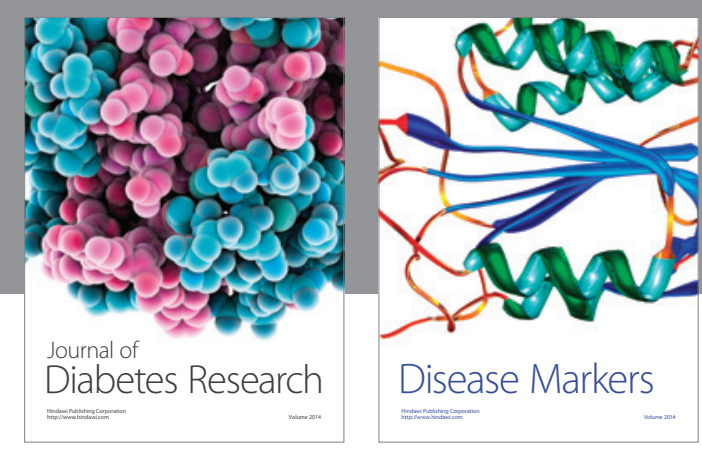

Disease Markers
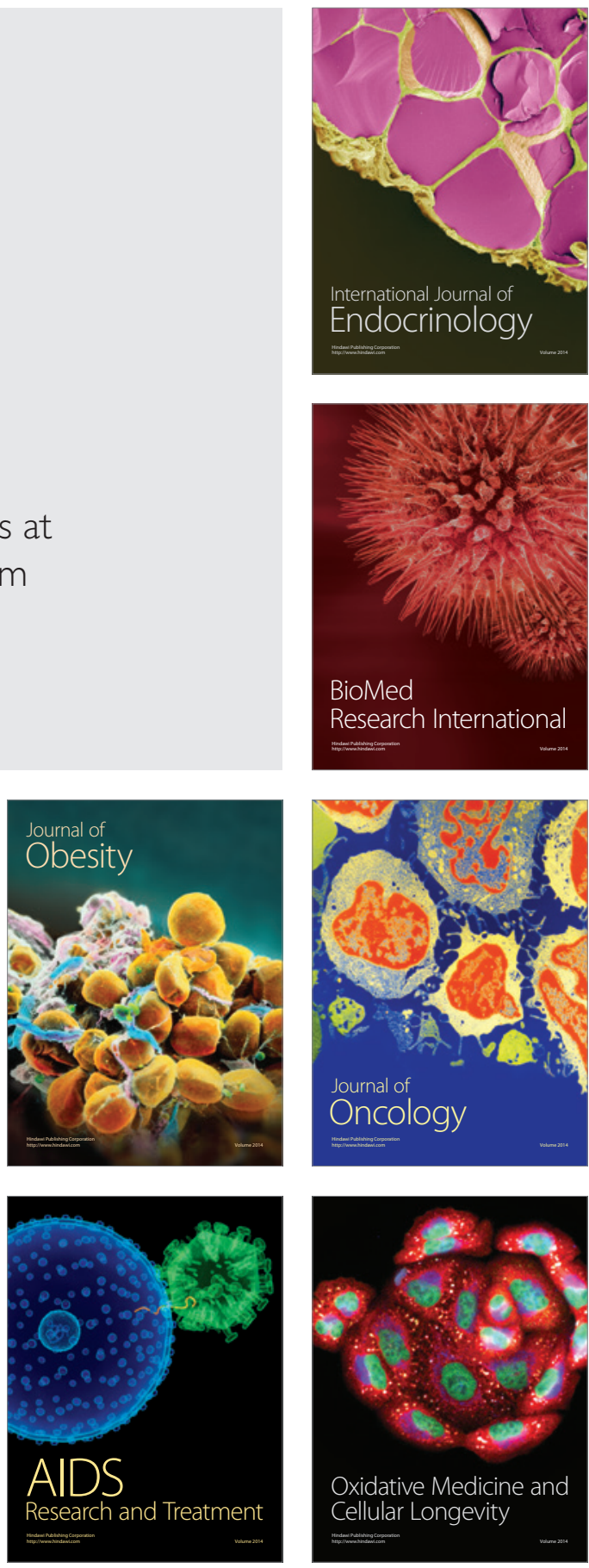